\title{
Reply to: "Correlation between paddy rice growth and satellite-observed methane column abundance does not imply causation"
}

\author{
Geli Zhang (1) ${ }^{1}$, Xiangming Xiao (10) ${ }^{2 凶}$, Jinwei Dong (1) ${ }^{3 凶}$, Yao Zhang (D) ${ }^{4}$, Fengfei Xin (1) ${ }^{5}$, Yuanwei Qin (1) ${ }^{2}$, \\ Russell B. Doughty ${ }^{6} \&$ Berrien Moore $1 \mathrm{II}^{7}$
}

REPLYING To Z. Zeng et al. Nature Communications https://doi.org/10.1038/s41467-021-21434-7 (2021)

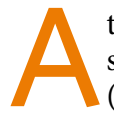
tmospheric methane concentration $\left(\mathrm{XCH}_{4}\right)$ measured by satellite-based sensors is affected by in situ $\mathrm{CH}_{4}$ emissions (local fluxes), atmospheric chemistry, and atmospheric transport (external fluxes). Based on annual paddy rice maps at the $500-\mathrm{m}$ spatial resolution, our study ${ }^{1}$ investigated the spatial and seasonal consistency between rice paddies and atmospheric methane concentration in monsoon Asia. In our study ${ }^{1}$, we implied that annual paddy rice maps at moderate spatial resolution $(500 \mathrm{~m})$ may be used to increase the accuracy of and reduce the uncertainty in modeling $\mathrm{XCH}_{4}$ dynamics over those areas with moderate to large proportions of rice paddy. We appreciate the comments from Zeng et al. ${ }^{2}$ as their work used the Greenhouse Gas Framework - Flux (GHGF-Flux) forward model, a state-of-the-art flux inversion system used by the National Aeronautics and Space Administration (NASA) Carbon Monitoring System program. Their results, analyses, and discussion offer insights into how the GHGF-Flux model assesses the relative roles of in situ $\mathrm{CH}_{4}$ emissions, atmospheric chemistry, and atmospheric transport in the spatial-temporal dynamics of $\mathrm{XCH}_{4}$. Here, we provide our responses to the two concerns raised by Zeng et al. ${ }^{2}$, which may further unveil the role of paddy rice agriculture in the seasonal dynamics and spatial distributions of $\mathrm{XCH}_{4}$ in monsoon Asia.

Zeng et al. ${ }^{2}$ analyzed the relative contributions of locally emitted $\mathrm{CH}_{4}$ fluxes and externally transported $\mathrm{CH}_{4}$ fluxes to the seasonal cycle of $\mathrm{XCH}_{4}$ in the four regions of interest (ROIs): Northeast China, Southeast China, Northwest India, and North Bangladesh. They reported that externally transported $\mathrm{CH}_{4}$ fluxes contributed more to the seasonal cycle of $\mathrm{XCH}_{4}$ than did locally emitted $\mathrm{CH}_{4}$ fluxes in Northeast China, Southeast China, and Northwest India, but the relative roles of these two $\mathrm{CH}_{4}$ fluxes were comparable in North Bangladesh ${ }^{2}$. Our study reported that the seasonal dynamics of $\mathrm{XCH}_{4}$ and paddy rice growth were consistent across the $0.5^{\circ}$ gridcells with moderate to high proportions of rice paddy (area percentage $>10 \%$ within gridcells) ${ }^{1}$. This discrepancy in the role of rice paddies in seasonal dynamics of $\mathrm{XCH}_{4}$ between Zeng et al. ${ }^{2}$ and our study ${ }^{1}$ can be attributed to three factors.

First, the area of the ROIs used in Zeng et al. ${ }^{2}$ (Fig. 1a) was substantially larger than that used in our study ${ }^{1}$. Larger ROIs have much lower proportions of rice paddy area (Fig. $1 \mathrm{~g}-\mathrm{n}$ ). Statistically, average values over very large ROIs would dampen localized seasonal variations, which often leads to failure to identify hot spots within ROIs ${ }^{3}$. Second, the spatial resolution of the gridded data we used in our study ${ }^{1}$ was finer than that used by Zeng et al. ${ }^{2}$. The GHGF-Flux $\mathrm{CH}_{4}$ inversion used by Zeng et al. ${ }^{2}$ was carried out at $2^{\circ} \times 2.5^{\circ}$ horizontal spatial resolution, which is much coarser than the spatial resolution of the $\mathrm{XCH}_{4}$ data from the SCIAMACHY sensors $\left(0.5^{\circ} \times 0.5^{\circ}\right)$ that comprised our ROIs ${ }^{1}$. Given that there are many land cover types in monsoon Asia, larger gridcells would have lower proportions of rice paddy area (Fig. $1 \mathrm{~g}-\mathrm{n}$ ), and would thus diminish the local contribution of $\mathrm{CH}_{4}$ emission from rice paddy on the seasonal cycle of $\mathrm{XCH}_{4}$. As shown in Fig. 1a by Zeng et al. ${ }^{2}$, the relative contribution of locally emitted $\mathrm{CH}_{4}$ fluxes to the seasonal cycle of $\mathrm{XCH}_{4}$ increased with the proportion of rice paddy area within the ROIs. The North Bangladesh ROI is a good example. Rice paddy in Bangladesh accounts for about $68 \%$ of the country's land area (Fig. 1e), and it occupies a large proportion $(22 \%)$ of the $2^{\circ} \times$ $2.5^{\circ}$ gridcells in the ROI (Fig. $1 \mathrm{~m}$ ) compared to the gridcells in the other ROIs (Fig. 1k, l, n). Thus, the comparable relative contributions of local and external $\mathrm{CH}_{4}$ fluxes to the seasonal cycle of

\footnotetext{
${ }^{1}$ College of Land Science and Technology, China Agricultural University, Beijing, China. ${ }^{2}$ Department of Microbiology and Plant Biology, and Center for Spatial Analysis, University of Oklahoma, Norman, OK, USA. ${ }^{3}$ Key Laboratory of Land Surface Pattern and Simulation, Institute of Geographic Sciences and Natural Resources Research, Chinese Academy of Sciences, Beijing, China. ${ }^{4}$ Climate and Ecosystem Sciences Division, Lawrence Berkeley National Laboratory, Berkeley, CA, USA. ${ }^{5}$ Ministry of Education Key Laboratory of Biodiversity Science and Ecological Engineering, Institute of Biodiversity Science, Fudan University, Shanghai, China. ${ }^{6}$ Division of Geological and Planetary Sciences, California Institute of Technology, Pasadena, CA, USA. ${ }^{7}$ College of Atmospheric and Geographic Sciences, University of Oklahoma, Norman, OK, USA. ${ }_{\text {email: xiangming.xiao@ou.edu; dongjw@igsnrr.ac.cn }}$
} 

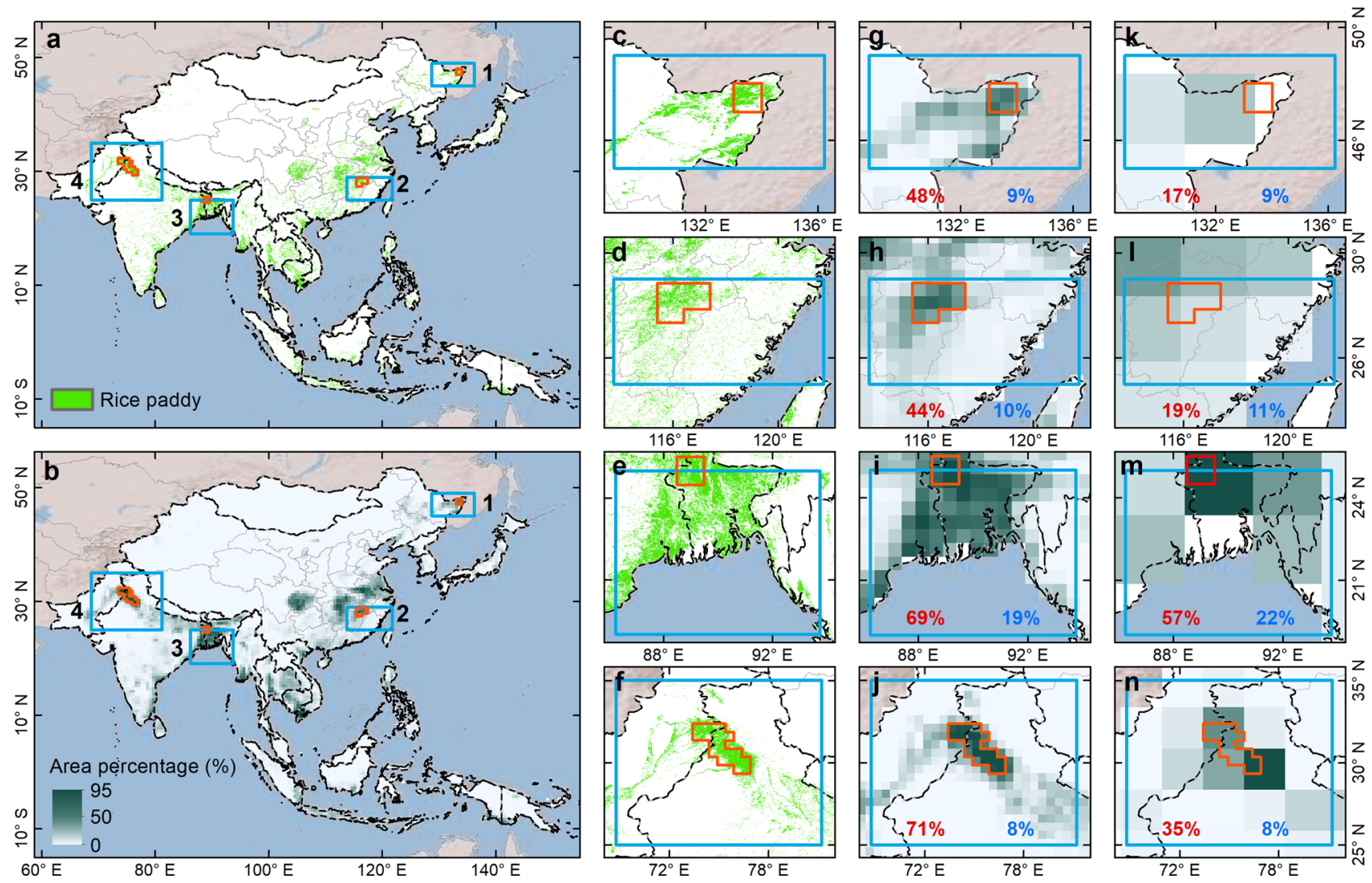

Fig. 1 Potential effects of different sizes of regions of interest (ROIs) with varied footprints of rice paddies. The red and blue ROls are from our study ${ }^{1}$ and Zeng et al. ${ }^{2}$, respectively. The paddy rice maps were retrieved from MODIS data with the $500-\mathrm{m}$ spatial resolution (a) and $0.5^{\circ}$ spatial resolution (b) in monsoon Asia in 2010, respectively. Detailed spatial distributions of rice paddies in local regions labeled with blue rectangles and spatial resolutions of $500 \mathrm{~m}(\mathbf{c}-\mathbf{f}), 0.5^{\circ}(\mathbf{g}-\mathbf{j})$, and $2^{\circ} \times 2.5^{\circ}(\mathbf{k}-\mathbf{n})$. The red and blue numbers show the mean of rice paddy area proportion in ROls with red and blue color, respectively.

$\mathrm{XCH}_{4}$ in the North Bangladesh ROI (see Fig. 1a in Zeng et al. ${ }^{2}$ ) are likely driven in part by the region's high rice paddy proportion. Third, the GHGF-Flux model used the CarbonTracker- $\mathrm{CH}_{4}$ emission from EDGAR 3.2FT2000 as prior $\mathrm{CH}_{4}$ emission estimates of rice paddy, enteric fermentation, and animal waste. The EDGAR dataset's estimates of $\mathrm{CH}_{4}$ emissions from rice paddy are based on paddy rice area from agricultural statistics at various administrative levels 4,5 , which often cannot resolve the spatial distribution of paddy rice area at a $0.5^{\circ}$ spatial resolution. The spatial heterogeneity of $\mathrm{CH}_{4}$ emission sources cannot be captured using larger ROIs, coarser gridcells, and inaccurate model inputs. In addition, $\mathrm{XCH}_{4}$ is theoretically calculated as the total $\mathrm{CH}_{4}$ across different altitudes. However, the SCIAMACHY $\mathrm{XCH}_{4}$ retrieval is mainly based on the short-wavelength infrared band (SWIR), which is more indicative of $\mathrm{CH}_{4}$ at lower altitudes down to the surface ${ }^{6}$.

Zeng et al. ${ }^{2}$ further analyzed the seasonal dynamics of $\mathrm{XCH}_{4}$ from the four ROIs and four latitudinal zones $\left(10^{\circ}\right.$ interval $)$ that were centered on the four ROIs during 2003-2011 (see Fig. 1b by Zeng et $\mathrm{al}^{2}$ ), and claimed that there were strong agreements between the ROIs and latitudinal zones. Unfortunately, the authors failed to recognize that the Southeast China ROI had very different seasonal dynamics between the $\mathrm{ROI}$ (two $\mathrm{XCH}_{4}$ peaks in one year) and latitudinal zonal $\mathrm{XCH}_{4}$ (one $\mathrm{XCH}_{4}$ peak in one year) (Fig. $1 \mathrm{~b}$ by Zeng et al. ${ }^{2}$ and Fig. 2 here). The timing of the two $\mathrm{XCH}_{4}$ peaks in one year is actually related to the double paddy rice cropping system in South China (Supplementary Fig. 1), which we explained in our study ${ }^{1}$. This noticeable twopeak seasonal dynamic in the Southeast China ROI further highlights the importance of annual paddy rice maps at moderate spatial resolution $(500 \mathrm{~m})$ in understanding the seasonal dynamics of paddy rice $\mathrm{CH}_{4}$ emissions and $\mathrm{XCH}_{4}$.

Our study reported that there were consistent spatial distributions between $\mathrm{XCH}_{4}$ and paddy rice area across those $0.5^{\circ}$ gridcells with relatively moderate to high proportions of rice paddy (area percentage $>10 \%$ within gridcells) $)^{1}$. Zeng et al. ${ }^{2}$ analyzed the spatial distributions of $\mathrm{XCH}_{4}$ and EDGAR-based $\mathrm{CH}_{4}$ emissions from agricultural and non-agriculture sectors for all $1^{\circ}$ gridcells in monsoon Asia in 2010 and reported that the spatial distribution of $\mathrm{XCH}_{4}$ correlated with $\mathrm{CH}_{4}$ emissions from both agricultural and non-agricultural sectors. We recognize that paddy rice area is one of many factors that affect the spatial distribution of $\mathrm{XCH}_{4}$ in dense rice paddy regions; however, EDGAR's use of agricultural statistical data at administrative levels (e.g., national, state or province) $)^{4,5}$ precludes accurate resolution of the geographic (or spatial) distribution of different $\mathrm{CH}_{4}$ emission sources. Furthermore, the $1^{\circ}$ gridcell analyses of the EDGAR data in Zeng et al..$^{2}$ cannot reflect the spatial heterogeneity of $\mathrm{CH}_{4}$ emissions from different sources within the gridcells. Thus, the higher consistency between nonagricultural $\mathrm{CH}_{4}$ emissions and $\mathrm{XCH}_{4}$ reported in Zeng et al. ${ }^{2}$ does not refute our finding on the role of $\mathrm{CH}_{4}$ emission from rice paddies. The finer spatial resolution data of $\mathrm{CH}_{4}$ emissions from rice paddies could rather improve the EDGAR data, and thus improve our understanding of the relative role of agricultural and non-agricultural $\mathrm{CH}_{4}$ emissions in the spatial distribution of $\mathrm{XCH}_{4}$.

In summary, we recognize the importance of the GHGF-Flux model for $\mathrm{CH}_{4}$ flux inversion, atmospheric chemistry, atmospheric transport, and attribution of $\mathrm{CH}_{4}$ emissions to various 

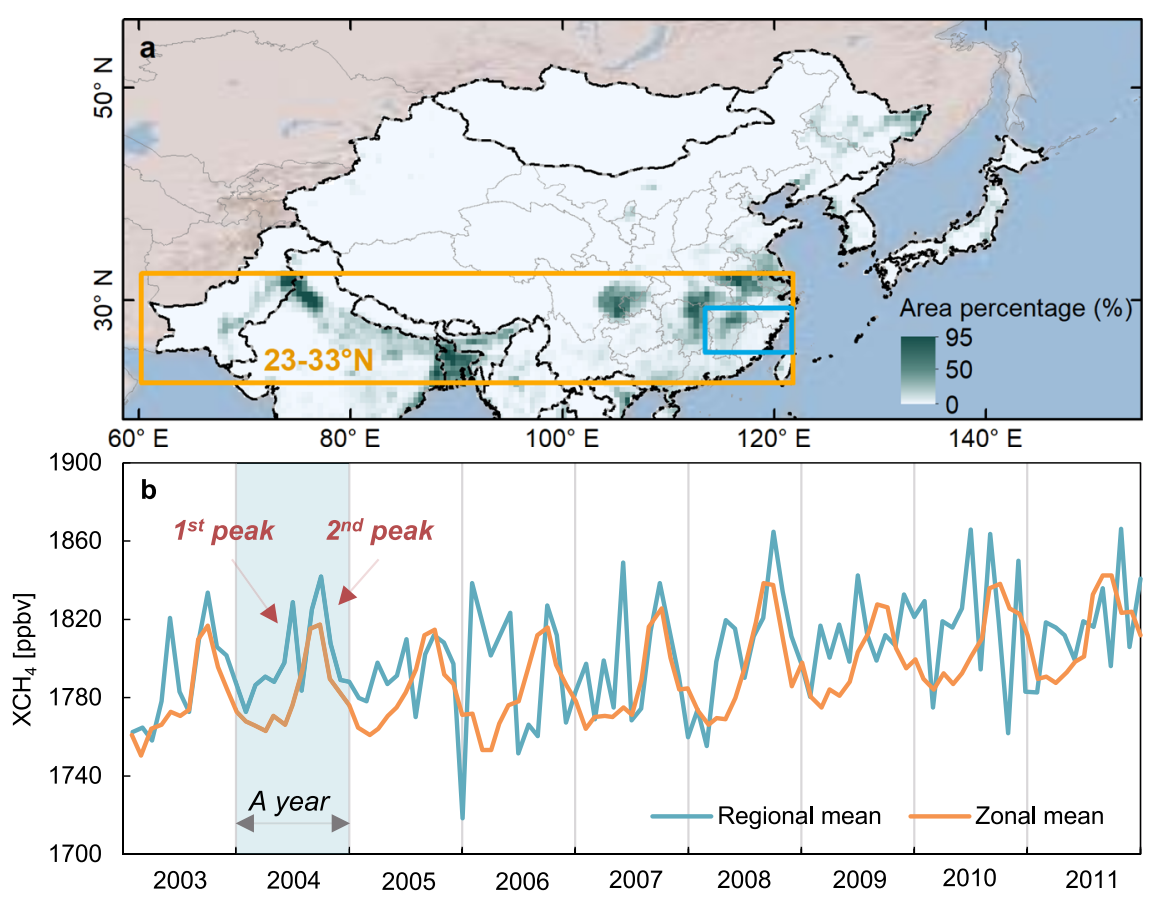

Fig. 2 Monthly averaged $\mathrm{XCH}_{4}$ in the region of interest (ROI) of Southeast China and the latitudinal zone centered on the ROI according to Zeng et al. ${ }^{2}$. a The MODIS-based paddy rice map at $0.5^{\circ}$ resolution in monsoon Asia in 2010 . The orange rectangle shows the latitudinal zone of $23^{\circ}-33^{\circ}$ $\mathrm{N}$ centered on the Southeast China ROI. The blue rectangle shows the boundary of the Southeast China ROI from Zeng et al. ${ }^{2}$. b Monthly averaged XCH $\mathrm{in}$ the $\mathrm{ROI}$ and the latitudinal zone according to Zeng et al. ${ }^{2}$. The regional mean in $\mathbf{b}$ is the averaged value of $\mathrm{XCH}_{4}$ in $\mathrm{ROI}$, and the zonal mean in $\mathbf{b}$ is the averaged $\mathrm{XCH}_{4}$ over the latitudinal zone centered on the ROI, which is from Zeng et al.'s paper'

sources. Together, the results from Zeng et al. ${ }^{2}$ using the GHGFFlux model and our study ${ }^{1}$ based on higher resolution paddy rice maps and satellite observations highlight the importance of the high-resolution paddy rice maps to understanding the spatial distribution and seasonal dynamics of $\mathrm{XCH}_{4}$. Annual paddy rice maps at moderate and high spatial resolutions can be used to further improve $\mathrm{CH}_{4}$ emission estimates from rice paddies in the EDGAR dataset and to better understand the relationships between the spatial distribution and seasonal dynamics of $\mathrm{XCH}_{4}$ from the TROPOspheric Monitoring Instrument (TROPOMI, $7 \times 7 \mathrm{~km}$ spatial resolution) and rice paddies in monsoon Asia.

\section{Data availability}

The paddy rice maps can be accessed by contacting Geli Zhang, Xiangming Xiao, or Jinwei Dong. All the relevant data from this study are also available from the corresponding authors upon request.

\section{Code availability}

The code used in this study can be obtained by contacting the corresponding authors.

Received: 2 July 2020; Accepted: 19 January 2021;

Published online: 19 February 2021

\section{References}

1. Zhang, G. et al. Fingerprint of rice paddies in spatial-temporal dynamics of atmospheric methane concentration in monsoon Asia. Nat. Commun. 11, 554 (2020).

2. Zeng, Z.-C., Byrne, B., Gong, F.-Y., He, Z. \& Lei, L. Correlation between paddy rice growth and satellite-observed methane column abundance does not imply causation. Nat. Commun. https://doi.org/10.1038/s41467-021-21434-7 (2021).

3. Liu, J. et al. Response to Comment on "Contrasting carbon cycle responses of the tropical continents to the 2015-2016 El Niño". Science 362, eaat1211
(2018)

4. Peng, S. S. et al. Inventory of anthropogenic methane emissions in mainland China from 1980 to 2010. Atmos. Chem. Phys. 16, 14545-14562 (2016).

5. Janssens-Maenhout, G. et al. EDGAR v4.3.2 Global Atlas of the three major greenhouse gas emissions for the period 1970-2012. Earth Syst. Sci. Data 11, 959-1002 (2019).

6. Hayashida, S. et al. Methane concentrations over Monsoon Asia as observed by SCIAMACHY: signals of methane emission from rice cultivation. Remote Sens. Environ. 139, 246-256 (2013).

\section{Acknowledgements}

This work was funded by research grants from the National Natural Science Foundation of China (41871349, 81961128002), and the U.S. National Science Foundation (1911955). We thank Qiang Zhang at China Agricultural University for preparing the figure for the Supplementary Information, and Sarah L. Xiao at the University of Oklahoma for language editing of the manuscript.

\section{Author contributions}

X.X., G.Z., J.D. and Y.Z. contributed to data analyses and writing the comments' reply. X. X., G.Z., J.D., Y.Z., F.X., Y.Q., R.D. and B.M. all took part in the discussion of the reply.

\section{Competing interests}

The authors declare no competing interests.

\section{Additional information}

Supplementary information The online version contains supplementary material available at https://doi.org/10.1038/s41467-021-21437-4.

Correspondence and requests for materials should be addressed to X.X. or J.D.

Peer review information Nature Communications thanks Hironori Arai, Dailiang Peng and other, anonymous, reviewers for their contributions to the peer review of this work.

Reprints and permission information is available at http://www.nature.com/reprints

Publisher's note Springer Nature remains neutral with regard to jurisdictional claims in published maps and institutional affiliations. 
(c) (i) Open Access This article is licensed under a Creative Commons Attribution 4.0 International License, which permits use, sharing, adaptation, distribution and reproduction in any medium or format, as long as you give appropriate credit to the original author(s) and the source, provide a link to the Creative Commons license, and indicate if changes were made. The images or other third party material in this article are included in the article's Creative Commons license, unless indicated otherwise in a credit line to the material. If material is not included in the article's Creative Commons license and your intended use is not permitted by statutory regulation or exceeds the permitted use, you will need to obtain permission directly from the copyright holder. To view a copy of this license, visit http://creativecommons.org/ licenses/by/4.0/.

(C) The Author(s) 2021 